\title{
Entrevista Inicial como Suporte para Intervenções em Grupos de Orientação a Pais
}

\author{
Maria Benedita Lima Pardo \\ Margarida Maria Silveira Britto de Carvalho \\ Ariane de Brito \\ Luciana Priscila Lima da Silva \\ Universidade Federal de Sergipe \\ São Cristóvão, SE, Brasil
}

\begin{abstract}
RESUMO
O uso de instrumentos de coleta de dados previamente ao planejamento de intervenções tem se revelado de fundamental importância nos trabalhos em Psicologia. A literatura destaca a inter-relação entre as fases de diagnóstico e intervenção, considerando que a avaliação deve ser feita antes, durante e mesmo após o término da intervenção. Este artigo apresenta os resultados obtidos em entrevistas iniciais com mães participantes de grupos de orientação realizados em uma clínicaescola. As questões colocadas nas entrevistas possibilitaram-lhes ampliar o relato de suas queixas, direcionando-as para aspectos referentes aos ambientes que a criança frequentava, para outros comportamentos e características dos filhos e para seu próprio comportamento enquanto educadora. Os resultados indicaram a necessidade de trabalhar a percepção da influência recíproca entre os comportamentos da mãe e da criança e refletir sobre a melhor forma de ajustá-los com o intuito de potencializar o desenvolvimento infantil.
\end{abstract}

Palavras-chave: Treinamento de pais; Entrevista; Ambientes sociais.

\begin{abstract}
Initial Interview as Support to Interventions in Parent Orientation Groups

The use of data collection instruments before the intervention planning is very relevant in the psychologist's work. The literature emphasizes the relation between the diagnosis and intervention phases. This article presents the results obtained with initial interviews applied to participant mothers in orientation groups offered in a psychological service. The questions posed lead the mothers to enlarge the information about their complaints directing their attention to aspects of environments where their children used to be, to other characteristics and behavior of the children and to their own behavior as an educator. The results reveal the need to discuss the mutual influence between mother's and children's behaviors in order to adjust them and contribute to the children's development.
\end{abstract}

Keywords: Parent training; interview; social environments.

\section{RESUMEN}

Entrevista Inicial de Apoyo para Intervenciones en Grupos de Orientacion a los Padres

El uso de instrumentos para recopilación de datos previos al planeamiento de intervenciones ha demostrado ser fundamental en los trabajos de Psicología. La literatura destaca la interrelación entre las fases de diagnóstico e intervención, teniendo en cuenta que la evaluación debe hacerse antes, durante e incluso después de la intervención. En este artículo se presentan los resultados obtenidos en las entrevistas iniciales con las madres que participan de grupos de orientación realizadas en una clínica-escuela. Las preguntas de las entrevistas les permite ampliar los informes de sus quejas, dirigiéndolas hacia aspectos relacionados con los ambientes que el niño frencuenta, para otros comportamientos y características de los niños y para su propio comportamiento como educador. Los resultados indican la necesidad de trabajar la percepción de la interacción entre el comportamiento de la madre y el niño y reflexionar sobre la mejor manera de ajustarlos con el fin de mejorar el desarrollo del niño.

Palabras clave: Entrenamiento de padres; entrevista; ambiente social. 
A partir da segunda metade do século vinte ocorre a pluralização da família contemporânea, que assume diversas configurações, entre elas: famílias nucleares, recompostas, monoparentais e homoafetivas. Segundo Böing, Crepaldi e Moré (2008), a família, entendida como um fenômeno complexo e dinâmico, assume diferentes composições, estruturais ou relacionais, o que dificulta a elaboração de um conceito único, que contemple as diferentes realidades.

Dessen (2010) pontua que, no Brasil, deve-se utilizar o termo família brasileira no plural por haver mais de um modelo de organização familiar, destacando assim a diversidade étnico-cultural e as importantes mudanças na estrutura, funcionamento e contexto dessas famílias. Salienta também que, na segunda metade do século vinte, simultaneamente às mudanças nos papéis sociais do homem e da mulher, as relações maritais e parentais também se modificavam, influindo na educação e no processo de socialização dos filhos. Anteriormente, as crianças eram mais passivas devido ao ensino da submissão aos pais e aos adultos em geral, por meio da utilização de práticas punitivas. À medida que a mulher assume uma nova postura materna, ocorre a valorização do diálogo e, ao mesmo tempo, o pai adquire uma postura mais flexível, com consequente redução das práticas punitivas.

Observa-se, na atualidade, ampla divulgação pelos meios de comunicação de informações a respeito da educação de crianças e do desenvolvimento infantil, as quais costumam gerar dúvidas sobre as melhores maneiras de criar os filhos, muitas vezes levando os pais a questionar o modelo de educação recebido em suas famílias de origem.

Campbell e Palm (2004) mencionam que os pais se preocupam profundamente com suas crianças e desejam desempenhar bem o papel de educadores Desde cedo, procuram acompanhar o crescimento de seus filhos, analisar os perigos a que estão expostos e a forma como adentram um mundo onde a mídia projeta violência e explicita a sexualidade. Alguns de seus questionamentos dizem respeito ao uso da punição física como disciplina, conduta agora proibida pelas leis de proteção à infância. Muitos estão conscientes das falhas de seus pais em sua educação e percebem o quanto essas posturas afetam suas vidas e a educação de seus filhos. Segundo esses autores, a educação pode dar suporte ao crescimento e desenvolvimento dos filhos, à medida que os pais se deparam com problemas específicos ou estressantes diante de mudanças no ciclo de vida familiar. Muitos enfrentam o desafio de dividir, de maneira equilibrada, as atividades que envolvem o cuidado com os filhos, o trabalho e a vida familiar, numa sociedade em constantes transformações.

Frequentemente, não se julgam preparados para lidar com situações problemáticas presentes na educação dos filhos e exigem, de si próprios, condutas assertivas. Não raro, recorrem à ajuda profissional. Weber, Brandenburg e Salvador (2006) defendem a necessidade de treinamentos práticos para que os pais assumam novas posturas comportamentais em prol da interação com os filhos. Nesse contexto, as clínicasescola ligadas aos cursos de psicologia constituem espaços que podem oferecer esse tipo de auxílio. É o caso do trabalho apresentado neste artigo, que é desenvolvido desde 2004 no Serviço de Psicologia Aplicada (SPA) da Universidade Federal de Sergipe (UFS).

\section{A PROPOSTA DOS GRUPOS DE ORIENTAÇÃO A PAIS}

A iniciativa de desenvolver o projeto Grupos de Orientação a Pais (GO) decorreu da necessidade de melhor atender famílias que buscavam, cada vez mais, atendimento psicológico para seus filhos, com queixas frequentes envolvendo a relação com os pais. Buscou-se, portanto, proporcionar discussões em grupos, a fim de favorecer intervenções psicoterapêuticas e oportunizar a inserção dos pais, cujos filhos ainda não estavam sendo atendidos, em um trabalho psicoeducacional.

Este trabalho fundamentou-se em princípios da psicologia da Aprendizagem e do Desenvolvimento e na abordagem bioecológica de Bronfenbrenner (1996). Segundo este autor, o desenvolvimento ocorre com base em influências de ambientes próximos (micro e mesossitema) e remotos (exo e macrossitema) e das interconexões entre ambos, sendo, portanto, necessário explorar o que pode estar ocorrendo em diferentes ambientes frequentados pela criança.

Baseou-se, também, em concepções adotadas por outros trabalhos de orientação a pais, como os de Colnago $(2014 ; 2000)$. Partindo do princípio de que era necessário realizar um levantamento das necessidades das famílias anteriormente ao planejamento das intervenções, essa autora as envolveu no processo de escolher e desempenhar as ações que julgassem mais adequadas para seus filhos, sob orientação do profissional. Seus estudos contribuíram para que, nesta investigação, o envolvimento dos pais fosse valorizado na escolha dos temas discutidos pelo grupo de pais.

O GO tem funcionado com uma programação de oito encontros, periodicidade semanal e duração 
de uma hora cada. As orientações e intervenções baseiam-se nas temáticas e situações trazidas pelas mães, cuja participação é ativa e enfatizada, tanto no grupo como em seus ambientes, onde fazem observações e experienciam novas formas de interação com os filhos.

Antes das sessões de intervenção, são feitas entrevistas iniciais de forma a identificar as queixas, as situações que as originam e as percepções da mãe a respeito da criança, de suas práticas educativas e possíveis alterações que deseja. Também é aplicado o Child Behavior Checklist (CBCL), (Achenbach \& Rescorla, 2001.) com o intuito de levantar suas percepções sobre o comportamento dos filhos. Ao final, são realizadas novas entrevistas, nas quais as mães avaliam mudanças comportamentais observadas na criança, em seus próprios comportamentos $\mathrm{e}$ nos ambientes em que vivem. Avaliam, também, a dinâmica do $\mathrm{GO}$, contribuindo com sugestões. O CBCL é então reaplicado, para aferir se houve melhora em relação às queixas iniciais. A análise dos vários GOs mostrou resultados positivos sob dois aspectos: em relação ao modo como as mães agiam com a criança e à percepção de seus filhos e de si próprias (Pardo, Carvalho \& Santos, 2014).

\section{A PROPOSTA DE ENTREVISTA INICIAL}

Os instrumentos de coleta de dados, ou seja, as entrevistas iniciais e finais, foram adaptados à abordagem teórica adotada, de modo a abranger os diferentes ambientes frequentados pela criança, o que favoreceu a coleta de informações sobre seu comportamento, do cuidador e sobre condições ambientais importantes que poderiam ser objeto de análise e discussões durante as intervenções. A importância desses instrumentos de diagnóstico no decorrer da intervenção é ressaltada por Silvares (2000), que destaca a inter-relação entre diagnóstico e tratamento, uma vez que a avaliação não deve ser realizada apenas antecedendo a intervenção, mas, também, durante e após seu término. Destaca-se, portanto, a relevância da entrevista inicial como marco norteador para este processo.

A entrevista inicial buscou identificar as principais queixas das mães em relação a seus filhos, quais comportamentos mais as incomodavam e em quais ambientes eram observados. Intencionava também que verbalizassem suas percepções sobre seus filhos e sobre si mesmas, enquanto participantes do processo educacional, com ênfase em suas práticas educativas, dificuldades enfrentadas para educação dos filhos e percepções sobre mudanças nesse processo. Teve, portanto, não apenas um caráter descritivo, mas estimulador da reflexão sobre as influências recíprocas da relação mãe-filho.

Bronfenbrenner (1996) menciona que a orientação bioecológica busca traduzir, em termos operacionais, a posição teórica de que "o que importa para o comportamento e desenvolvimento é o ambiente conforme ele é percebido (grifo do autor), e não como ele poderia existir na realidade objetiva" (p. 6). Esta colocação reafirma nossa experiência com a entrevista inicial como fator de mudança visto que leva à reflexão de suas experiências enquanto mãe e educadora.

Dentre as questões colocadas, as referentes às queixas solicitavam que fossem enumeradas de acordo com o seu grau de importância e ambientes em que ocorriam. Essas questões direcionavam para relatos de aspectos negativos percebidos e eram seguidas por outras que ampliavam o foco dos relatos, de modo a viabilizar a introdução de discussões sobre outros aspectos comportamentais da criança e seu modo de ser. Em seguida, as questões conduziam para a análise das mães sobre seus comportamentos na relação com o filho.

Este artigo tem por objetivo apresentar os resultados obtidos nas entrevistas iniciais com mães que participaram de grupos no período de 2010 e 2013 e, com base nos mesmos, delinear características do trabalho a ser desenvolvido no decorrer das atividades dos grupos.

\section{MÉTODO}

\section{Participantes}

Foram analisadas as entrevistas de 36 participantes, dentre eles mães, um pai e outros parentes ou cuidadores, tais como avós e tias, os quais exerciam as funções de mãe em relação às crianças. Para preservação do anonimato, os participantes serão designados com a letra $\mathrm{P}$ seguida de números ( $\mathrm{P} 1$ até $\mathrm{P} 36)$ no decorrer do texto.

Eles foram selecionados de acordo com os seguintes critérios: renda familiar de até três salários mínimos e encaminhamento de seus filhos de até 12 anos para atendimento psicoterápico no SPA. Suas características gerais, assim como as de seus filhos, no que diz respeito aos dados demográficos e de participação no GO estão na Tabela 1. Observa-se que, dentre aqueles que informaram a idade, $25 \%$ tinham entre 31 e 40 anos, 52,8\% eram casados, $69,5 \%$ possuíam ensino fundamental ou médio. Quanto à participação no GO, $86,1 \%$ frequentaram o grupo. Em relação aos dados das crianças, a maioria era do sexo masculino (72.2\%), com idade entre 6 e 10 anos $(44,4 \%)$. 
TABELA 1

Caracterização dos participantes e das crianças, segundo dados demográficos e de participação no GO

\begin{tabular}{llc}
\hline Variável & \multicolumn{1}{c}{ Nível } & $\begin{array}{c}\text { Distribuição (\%) } \\
n=36\end{array}$ \\
\hline Idade (anos) & $20-30$ & 8,3 \\
& $31-40$ & 25,0 \\
& $41-50$ & 11,1 \\
& Acima de 50 & 2,8 \\
Estado Civil & Não informado & 52,8 \\
& Solteiro & 27,8 \\
& Casado & 52,8 \\
Escolaridade & Separado & 11,1 \\
& Não informado & 8,3 \\
& Ensino Fundamental & 30,6 \\
& Ensino Médio & 38,9 \\
& Ensino Superior & 5,6 \\
Sexo da criança & Não Informado & 19,4 \\
& Não estudou & 5,6 \\
Idade da criança & Feminino & 27,8 \\
& Masculino & 72,2 \\
& 1 a 5 & 22,2 \\
Frequentou GO & 6 a 10 & 44,4 \\
& Acima de 10 & 27,8 \\
& Sim & 86,1 \\
& Não & 13,9 \\
\hline
\end{tabular}

\section{Considerações éticas}

O projeto foi aprovado pelo Comitê de Ética e Pesquisa da Universidade Federal onde a pesquisa foi realizada, como consta do protocolo $\mathrm{N}^{\mathrm{O}} \mathrm{CAAE}-$ 0014.0.107.000-10. Ao serem convidadas para participar do GO, as mães foram esclarecidas sobre os objetivos da pesquisa e seus direitos quanto ao sigilo de identidade e à liberdade de não mais participarem no momento em que assim o desejassem. Após os esclarecimentos, todas assinaram o Termo de Consentimento Livre e Esclarecido.

\section{Local}

As coletas de dados foram realizadas no Serviço de Psicologia Aplicada (SPA), órgão vinculado ao Departamento de Psicologia de uma Universidade Federal.

\section{Instrumentos}

Roteiro da entrevista inicial: elaborado pelas próprias autoras, composto por 18 questões que abordavam as seguintes informações: identificação do entrevistado e seu grau de parentesco com a criança, dados pessoais de ambos, heredograma da família, queixas relativas à criança, dinâmica familiar, vida escolar do menor, bem como seu comportamento em outros ambientes, práticas educativas utilizadas e expectativas em relação ao grupo.

\section{Procedimentos}

Inicialmente, as mães e/ou cuidadores que possuíam fichas de inscrição para atendimento de seus filhos no SPA foram contatados e convidados a participar do grupo de orientação a pais (GO). No primeiro contato, foram informados sobre o objetivo e funcionamento do grupo, bem como sobre o dia e horário dos encontros. Foram, então, agendadas as entrevistas com os interessados antes do início do grupo, em datas e horários por eles escolhidos. Após a realização das entrevistas, cinco mães que inicialmente tinham manifestado interesse em participar não compareceram às reuniões do grupo.

\section{Análise dos dados}

Os dados das entrevistas foram categorizados com base na análise de conteúdo (Bardin, 2011), segundo os critérios: para nomeação das categorias, foram utilizados termos já conhecidos na área de treinamento de pais; para inclusão dos dados nas mesmas, foi verificada a similaridade de conteúdo dos relatos. A seguir, esses resultados foram inseridos no programa estatístico SPSS (Statistical Package for the Social Sciences, versão 19) para obtenção de frequências e porcentagens.

\section{RESULTADOS E DISCUSSÃO}

\section{Queixas}

As queixas foram analisadas com relação à sua frequência e ordem em que foram colocadas.

A mais frequente foi 'Problemas de Estudo' (25\%), seguida de 'Desrespeito a Regras' $(22,2 \%)$ e 'Comportamento Agressivo' (19,4\%). Outras queixas verbalizadas com menor frequência foram 'Problemas de Atenção/Agitação' e 'Ansiedade', com 13,9\% e $11,1 \%$, respectivamente. Os 'Problemas de Estudo', de acordo com as falas das mães, foram relacionados ao baixo desempenho na escola, à falta de atenção e a dificuldades de memória: "Está na quinta série e não sabe de nada" (P2); "É disperso, não se concentra em nada" (P8); "Ele é esquecido demais" (P14).

Os relatos acima revelam que as mães atribuem a responsabilidade de aprender as próprias crianças. Ao serem questionadas sobre sua participação em reuniões da escola ou a respeito de conversas com as professoras, a maioria referiu não participar. Demonstram também ausência de contato com as professoras, uma vez que apenas relataram receber bilhetes escritos pelas mesmas contendo reclamações a respeito do comportamento ou rendimento escolar da criança. 
Relatos de situações de 'Desrespeito a Regras' também foram citados pelas mães, que utilizaram as seguintes expressões:" $E$ uma criança boa, mas não aceita regras, não aceita disciplina (...) em casa é tudo organizado por horário, mas ele não aprende apesar de eu ensinar muito" (P3); "Responde ao pai, sendo 'grosso'com ele. Só quer fazer o que ele quer..." (P21).

Quanto ao 'Comportamento agressivo', verbalizaram: "Tudo ele destrói, o pai compra as coisas e ele quebra. Tudo o que ele quer ver, ele quebra, quebra os brinquedos" (P16); "Ele é agressivo e passou a xingar. Reage com violência com a irmã e com as outras crianças" (P18).

D’Abreu e Marturano (2010), em revisão de 18 estudos que abordaram a associação entre comportamentos externalizantes e baixo desempenho escolar, encontraram que tal associação expressa mau prognóstico às crianças, tais como problemas acadêmicos, de comportamento antissocial e até de transtornos psiquiátricos. Assim, as autoras enfatizam a importância da compreensão e do trabalho sobre essa associação, de modo que formas mais assertivas de tratamento e prevenção possam ser desenvolvidas.

Em relação aos ambientes onde essas queixas ocorriam, a Tabela 2 evidencia aumento de frequência de indicações à medida que o problema se estende para outros ambientes além da casa e escola, indicando perda de controle da mãe sobre o comportamento do filho. Assim, P3 relatou que a desobediência e o comportamento de mentir ocorriam em casa, na escola, no shopping e no mercado, enquanto P11 referiu que a agitação era comum em casa, na rua, na escola e em todos os lugares.

TABELA 2

Frequência e percentual dos ambientes onde ocorriam as queixas

\begin{tabular}{lcc}
\hline Ambiente onde aparece & Frequência & Percentual (\%) \\
\hline Em casa & 5 & 13,9 \\
Escola & 5 & 13,9 \\
Casa e escola & 8 & 22,2 \\
Vários ambientes & 13 & 36,1 \\
Não informado & 5 & 13,9 \\
Total & 36 & 100 \\
\hline
\end{tabular}

Segundo Bronfenbrenner(1996), o desenvolvimento deve ser considerado em sua relação de reciprocidade com o ambiente, incluindo as interconexões entre o ambiente imediato e as influências de ambientes mais amplos. Cada local apresenta peculiaridades que podem ou não favorecer determinados comportamentos. A variabilidade observada nas relações entre com- portamento e ambiente emerge nos relatos iniciais das mães, embora a maioria não verbalize, de modo explícito, que o comportamento do filho modifique conforme o ambiente; com frequência, costumam atribuir exclusivamente à criança a responsabilidade por seu comportamento inadequado.

D'Abreu e Marturano (2010) alertam para o modelo explicativo da inter-relação entre comportamentos e ambientes. Para essas autoras, o modelo causal linear, que prevê que determinados fatores conduzem a certos resultados, precisa ser substituído por outro sistêmico, multidimensional, transacional e evolutivo, que considere as especificidades da criança e as particularidades dos distintos ambientes, bem como as modificações nessas variáveis ao longo do tempo.

Outro aspecto a ser considerado é a generalização do comportamento para vários ambientes, evidenciada pela alta frequência de respostas na categoria 'Vários ambientes'. Esses relatos indicam que a criança está obtendo reforçadores em diversas situações, o que exige analisar as características destes ambientes a fim de planejar estratégias diferenciadas com vistas à modificação do comportamento considerado inadequado.

As mães também avaliaram a importância da queixa apresentada, sendo que $86 \%$ relataram como tendo 'muita importância', o que inclusive evidencia a relevância desta queixa e permite compreender o que as motivou a buscar ajuda no grupo de orientação.

Do total, 26 mães $(72,2 \%)$ apresentaram uma segunda queixa, sendo as mais frequentes 'Retraimento' e 'Desrespeito a regras' (13,9\%), seguidas de 'Comportamento agressivo' (11,1\%). Em relação aos locais onde eram observadas, a categoria mais indicada também foi 'Vários Ambientes' (30,6\%). Quanto à importância, 58,3\% avaliaram como 'muito importante'.

Apenas 11 mães (30,5\%) apresentaram uma terceira queixa, sendo a mais frequente 'Comportamento Agressivo' (13,9\%). Quanto aos locais, os mais indicados foram 'Em casa' $(11,1 \%)$, seguido por 'Vários ambientes' $(8,3 \%)$. Com relação à importância, a maioria foi avaliada como sendo de 'muita importância' (22,2\%).

\section{Fale sobre seu filho, como ele é}

A fim de complementar informações sobre as queixas trazidas, as mães foram solicitadas a falar sobre seu filho, como ele era, segundo suas perspectivas. A Tabela 3 evidencia que seus relatos estiveram relacionados a aspectos físicos, psicológicos e comportamentais, acompanhados de avaliações positivas e negativas. Pode-se também observar que 
nos diferentes aspectos relatados, a conotação negativa sempre predominou. Destacaram-se os 'aspectos comportamentais negativos' $(75 \%)$, tais como chorar, responder, gritar, bater em pessoas, seguidos dos 'aspectos psicológicos negativos' (47,2\%), como nervosismo, dificuldade de aprendizagem, desatenção e agitação.

TABELA 3

Percentual dos aspectos físico, psicológico e comportamental citados pelos participantes

\begin{tabular}{lrcc}
\hline & $\begin{array}{c}\text { Aspecto } \\
\text { Físico }\end{array}$ & $\begin{array}{c}\text { Aspecto } \\
\text { Psicológico }\end{array}$ & $\begin{array}{c}\text { Aspecto } \\
\text { Comportamental }\end{array}$ \\
\hline Positivo & $5,6 \%$ & $11,1 \%$ & $5,6 \%$ \\
Negativo & $19,4 \%$ & $47,2 \%$ & $75 \%$ \\
Positivo e Negativo & $0 \%$ & $36,1 \%$ & $8,3 \%$ \\
Não se refere & $75 \%$ & $5,6 \%$ & $11,1 \%$ \\
Total & $100 \%$ & $100 \%$ & $100 \%$ \\
\hline
\end{tabular}

Esta tabela mostra ainda que, em relação aos aspectos psicológicos, $36,1 \%$ das mães relataram simultaneamente fatores positivos e negativos, o que indica uma visão mais ampliada sobre a criança, compreendendo não só problemas, mas também suas qualidades. Como exemplos, temos as seguintes falas: "E., quando tinha três anos, chorava e era muito nervoso. É um menino muito criativo, tem facilidade em fazer amizades. Tem dificuldades para falar, troca as letras. É um pouco agitado" (P9); "A minha filha é doce, meiga, carinhosa. Está meio nervosa, não dorme direito, desobediente, teimosa" (P17).

Por outro lado, os 'aspectos físicos negativos' estavam relacionados a doenças, como verminoses, epilepsia e tomar remédio. Os poucos 'aspectos físicos positivos' relacionaram-se à aparência da criança: " $E$ ' morena, tem cabelos longos" (P6); "É alta e magricela. É bonita, é a coisa mais linda da mãe" (P33).

Caminha e Pelisoli (2007) alertam para a necessidade de se conhecer e trabalhar as principais crenças e expectativas dos pais em relação aos filhos, pois há, frequentemente, expectativas irrealistas que, se não trabalhadas continuarão a ser fonte de frustrações e conflitos nas interações. Outras pesquisas tem mostrado ser frequente a necessidade de esclarecimentos sobre o que deve ser esperado da criança, de acordo com sua faixa de idade, e também o desenvolvimento de um trabalho que os estimule a perceber que os comportamentos da criança estão relacionados às situações e pessoas com as quais interage (Pardo \& Carvalho, 2011, 2012; Pardo, Carvalho, \& Santos, 2014).

Segundo Friedberg e McClure (2004), os pais, em geral, esperam demais ou muito pouco de seus filhos, o que gera conflitos. Muitos confundem comportamento desejável com o esperado e exigem constantemente um padrão pouco provável de ser atingido, como no caso da obediência incondicional a todas suas solicitações. Uma vez alertados para essas diferenças, começam a perceber que mantinham uma visão distorcida, para o lado negativo, de seus filhos, ou seja, em muitas situações o filho obedecia à regra, mas ao seu modo.

\section{O que as mães modificariam em seus filhos}

Foi questionado às mães o que gostariam, se fosse possível, de modificar em seus filhos. Nas respostas, predominaram aspectos psicológicos (22,2\%), comportamentais $(22,2 \%)$ ou ambos $(27,8 \%)$. Observase que a indicação dos aspectos a serem modificados está coerente com as informações complementares às queixas relatadas no tópico anterior, em que as mesmas categorias foram mais frequentemente mencionadas. A seguir, são apresentadas algumas falas que expressam cada uma dessas categorias, respectivamente. "Queria que meu filho tivesse mais atenção e mais respeito por mim" (P12); "O choro, que me irrita bastante, e a desobediência" (P17); "A desobediência, a mentira, queria que ele se conscientizasse para melhorar a própria saúde" (P3).

Apesar de terem apresentado queixas, quatro mães $(11,1 \%)$ verbalizaram que não modificariam nada em seus filhos. Por outro lado, três $(8,3 \%)$ relataram desejo de alterar tudo. Essas respostas indicam posições bastante diferenciadas quanto à visão materna sobre as crianças. A afirmativa 'modificaria tudo' generaliza os problemas apresentados e sinaliza para um olhar bastante negativo. $\mathrm{O}$ 'não modificaria' indica aceitação da criança como ela é, apesar das queixas: "Modificaria a filha toda. Faria dela uma pessoa bem estudiosa, nem nervosa, nem inquieta, nem desatenta" (P2); "Tudo. A preguiça, falta de vontade, comportamentos desagradáveis. A violência". (P18); "Nada, só queria que ele aprendesse" (P26).

É interessante destacar que três mães, em vez de indicarem o que gostariam de mudar na criança, relataram necessidade de modificações em si mesmas, tal como mostram suas falas: "Mudaria a forma de lidar com meu filho, seria menos tirana, daria mais carinho" (P5); "Mudaria meu jeito de ser, daria mais atenção a meu filho" (P6); "Só o ensinamento" (P19). Esses relatos revelam que o momento da entrevista inicial, quando houve a possibilidade de dialogar sobre as características da criança e suas relações com os ambientes, favoreceu que refletissem sobre suas atuações relacionadas aos comportamentos do filho que as preocupavam. 


\section{Como as mães agem em relação à educação de seu filho}

Conhecer as práticas e os estilos parentais utilizados pelos pais é relevante na medida em que fornece informações para compreender a dinâmica familiar e a interação com seus filhos (Valentini \& Alchieri, 2009). O modo como agem na educação de seus filhos, isto é, suas práticas e estratégias, interfere diretamente no desenvolvimento e comportamento da criança. Quando positivas, as práticas favorecem esse desenvolvimento e contribuem para evitar o aparecimento e/ou manutenção de problemas de interação entre ambos; em contrapartida, quando negativas, configuram fatores de risco para o desenvolvimento infantojuvenil (Patias, Siqueira, \& Dias, 2013; Bolsoni-Silva \& Loureiro, 2011).

Nesse sentido, a maioria das mães relatou ter ações positivas $(33,3 \%)$, positivas e negativas $(30,6 \%)$ e estratégias negativas $(19,4 \%)$. A alta frequência nas duas primeiras categorias revela que já apresentavam modos de pensar que valorizavam as práticas positivas (como o diálogo, o incentivo à criança e o estabelecimento de limites), mas possivelmente se sentiam inseguras em relação ao seu uso e, por isso, procuravam um espaço para discuti-las e esclarecer suas dúvidas.

Weber, Brandenburg e Salvador (2006) encontraram resultados semelhantes em sua pesquisa quanto às práticas positivas, mas ressaltam a necessidade de discutir com os pais a funcionalidade das mesmas de modo que compreendam as implicações de seus comportamentos em relação ao filho.

No presente estudo, alguns relatos sinalizam para adoção de algumas importantes estratégias: "Educo do jeito que acho certo. Antes batia, mas agora converso e coloco de castigo, e tiro tudo que ele gosta" (P8); "Converso muito com E., oriento. Estou sempre corrigindo quando ele fala alguma palavra errada. As vezes bato, mas me arrependo depois" (P9).

Já as mães que relataram ações negativas mencionaram usar práticas do tipo: impedir várias ações da criança, bater, colocar de castigo, tirar tudo o que ela gosta:"Não deixo que ela faça algumas coisas só, como o banho. Não deixo que mexa nas coisas. Chamo muito atenção dela em relação à sujeira, inclusive quando está brincando. Nego quando ela me chama para brincarmos juntas" (P5); "Brigo, mas também converso e oriento. Quando perco a paciência, bato" (P12).

$\mathrm{Na}$ categoria 'outros modos de agir', relataram dúvidas e, às vezes, omissão em relação ao comportamento da criança considerado problema: "Converso, mas não adianta, também já bati muito. Não sei mais como lidar, pois ele não tem mais limite para comer e para falar. Eu faço que não vejo" (P4).

Para Patias, Siqueira e Dias (2013), muitos pais acreditam ser esta a melhor forma para educar, principalmente porque desconhecem outros meios ou porque foram assim educados. Nesse sentido, os grupos de orientação tornam-se relevantes na medida em que possibilitam reflexões acerca de novas práticas educativas ou alternativas que favoreçam o desenvolvimento da criança e as interações pais e filhos.

\section{Dificuldade para criar o filho}

Quando questionadas sobre eventual dificuldade para criar seus filhos, a maioria respondeu positivamente $(63,9 \%)$, seguida da resposta 'às vezes' $(19,4 \%)$ e de 'não' (16,7\%). A elevada frequência da resposta 'sim' evidencia que um dos fatores motivacionais para participação no grupo de orientação seria a possibilidade de superar essas adversidades. Entre as que responderam sim, a maioria $(43,47 \%)$ relatou que a principal dificuldade residia no comportamento da criança, descrevendo a forma como ele agia e como gostaria que se comportasse. "Gostaria que ele comesse menos e falasse menos" (P4); "Gosta de chamar atenção e é muito bruta" (P23); "Não colabora em casa, está desobediente" (P30).

As mães que responderam 'às vezes' $(19,4 \%)$, também indicaram necessidade de alterar o modo de agir do cuidador, ou seja, também estavam em busca de orientações para formas mais apropriadas de educação. "Eu acho dificil ensinar para ele as coisas" (P19); "Não sei como chamar atenção dela e dizer não" (P17); "Me sinto perdida, não sei que atitude tomar" (P28).

Pode-se destacar ainda que as dificuldades em educar estão também relacionadas às transformações que vêm ocorrendo na sociedade no que diz respeito ao exercício da parentalidade. Para Weber, Brandenburg e Salvador (2006), é de grande importância que os pais compreendam os ciclos intergeracionais e suas diferenças, ou seja, o modo como foram educados por seus pais e as práticas que estão adotando com os filhos. Tal entendimento ajuda a perceber a origem de algumas de suas ações e facilita mudá-las. Lidar com as demandas parentais e conciliá-las com os problemas do cotidiano torna o papel do pai/mãe ainda mais desafiador. As dificuldades originam-se de um conjunto de fatores interligados e as discussões nos grupos de orientação podem contribuir para equilibrá-los, especificamente quanto às dificuldades e insegurança na hora de educar. 


\section{O que as mães modificariam em si próprias em relação ao filho}

Solicitou-se, também, que relatassem o desejo de modificar algo em si mesmas em relação ao filho. As respostas mais frequentes estiveram relacionadas aos aspectos do cuidador, referindo-se à necessidade de mudanças no 'comportamento do cuidador' $(69,4 \%)$. Responderam que não mudariam $16 \%$ delas e $8,3 \%$ não responderam. Outras modificações apontadas com menor frequência estiveram relacionadas a aspectos do cuidador e da criança $(2,8 \%)$. "Me policiaria nas atitudes, não gritaria, não bateria e não poria de castigo" (P1); "Mudaria a forma de lidar com o filho, seria menos tirana, daria mais carinho" (P5); "Poderia ser mais paciente, mas acha que o problema é no filho" (P4); "Não mudaria nada" (P20).

Essas falas confirmam que o momento da entrevista inicial é fecundo para o desenvolvimento de reflexões sobre seu papel na educação dos filhos. Esse processo permanece no decorrer das reuniões, chegando a produzir relatos de alterações de comportamentos no lidar com as crianças (xxx).

\section{CONSIDERAÇÕES FINAIS}

As mães que procuram os grupos de orientação chegam frequentemente ansiosas por informações sobre problemas que vivenciam, os quais são inicialmente atribuídos à criança. As questões propostas na entrevista inicial visam possibilitar que ampliem o seu olhar, direcionando a atenção para aspectos dos ambientes frequentados pela criança, para outros comportamentos ou características de seus filhos e para seu próprio comportamento enquanto educadora. Têm também o intuito de fornecer ao entrevistador informações sobre como as mães caracterizam e avaliam as queixas relatadas, quais fatores consideram relevantes para as mesmas e os recursos de apoio e de conhecimento que já possuem ou dos quais necessitam. São informações relevantes para escolha e aplicação das estratégias de intervenção nos encontros subsequentes do grupo.

Deve-se ressaltar a importância de adotar a abordagem bioecológica (Bronfenbrenner, 1996) como suporte para esses questionamentos, pois leva os entrevistadores a uma constante preocupação em solicitar informações sobre a relação entre o comportamento da criança e o ambiente onde se encontra, incluindo aí o comportamento de outras pessoas. Trata-se de obter informações que forneçam suporte para o trabalho relativo ao modo como mães ou outras pessoas significativas estão reagindo aos comportamentos da criança. Para alterar seu papel na educação do filho, é importante que as mães percebam também seus comportamentos e como eles afetam a criança. Vários relatos apresentados indicam que essa percepção pode ser estimulada desde a entrevista inicial.

Ao analisar o funcionamento das díades no processo de desenvolvimento, Bronfenbrenner (1996) enfatiza aspectos que podem influir positivamente, a saber: reciprocidade, equilíbrio do poder e relação afetiva. A reciprocidade implica que, no curso de uma atividade conjunta, um membro necessite ajustar suas ações às do outro. Os dados da entrevista inicial revelam a importância das intervenções estimularem as mães a observar os comportamentos dos filhos em diferentes situações, não só para identificar as habilidades da criança como para adequar as regras às possibilidades do filho, estimulando seu caminhar em direção a comportamentos mais amadurecidos. Assim, trabalham-se formas de solicitação mais adequadas às especificidades da criança.

Com frequência, os processos diádicos recíprocos implicam que um dos participantes seja mais influente que o outro. Essa relação, segundo Bronfenbrenner (1996), é conhecida como equilíbrio do poder. Há evidências sugestivas de que o desenvolvimento é favorecido quando o equilíbrio de poder gradualmente pende para o lado da pessoa em desenvolvimento. Os relatos das mães podem contribuir para identificação dos tipos de instrução, bem como das atividades mais adequadas ao nível de desenvolvimento da criança.

A respeito da relação afetiva, Bronfenbrenner (1996) ressalta a ocorrência e manifestação de sentimentos positivos, negativos, ambivalentes ou assimétricos de uma pessoa em relação a outra à medida que as interações ocorrem. Sendo positivos e recíprocos, a probabilidade de propiciarem o desenvolvimento é maior. Neste estudo, as mães relataram sentimentos positivos por seus filhos e, nesse sentido, as discussões do GO são importantes para refletir sobre eles e, também, sobre as avaliações e sentimentos negativos e como expressá-los sem magoar a criança, visando fortalecer a compreensão das situações que precisam ser alteradas por ambos os lados, a criança e a mãe, e favorecendo as mudanças na direção dos comportamentos desejáveis.

Ainda no que diz respeito à reciprocidade, é importante ressaltar que requer mudanças nos dois lados; assim, conforme a criança muda e se torna mais amadurecida, deverão também ocorrer mudanças nos comportamentos da mãe propiciando-lhe oportunidades de melhor desempenhar seu papel de educadora. Os trabalhos de intervenção do $\mathrm{GO}$, com base nesses princípios, buscarão contribuir para o alcance de tais objetivos. 


\section{REFERÊNCIAS}

Achenbach, T. M. \& Rescorla, L. A. (2001). Manual for the ASEBA School-Age Forms \& Profiles. Burlington, VT: University of Vermont, Research Center for Children, Youth \& Families.

Bardin, L. (2011). Análise de conteúdo. Lisboa: Edições 70.

Böing, E., Crepaldi, M. A., \& More, C. L. O. O. (2008). Pesquisa com famílias: Aspectos teórico-metodológicos. Paidéia, 18(40), 251-266. http://dx.doi.org/10.1590/S0103-863X2008000200004

Bolsoni-Silva, A. T. \& Loureiro, S. R. (2011). Práticas educativas parentais e repertório comportamental infantil: comparando crianças diferenciadas pelo comportamento. Paidéia (Ribeirão Preto), 21, 61-71. http://dx.doi.org/ 10.1590/S0103-863X2011000100008

Bronfenbrenner, U. (1996). A ecologia do desenvolvimento humano: experimentos naturais e planejados. Porto Alegre: Artes Médicas.

Caminha, M. G. \& Pelisoli, C. (2007). Treinamento de pais: aspectos teóricos e clínicos. In Caminha, R. M. \& Caminha, M. G. A prática cognitiva na infância (pp. 274-289). São Paulo: Roca.

Campbell, D. \& Palm, G. F. (2004). Group parent education: promoting parent learning and support. California: Sage.

Colnago, N. A. S. (2000). Orientação para pais de crianças com síndrome de down: elaborando e testando um programa de intervenção. (Tese de Doutorado) Faculdade de Filosofia, Ciências e Letras de Ribeirão Preto, Universidade de São Paulo, Ribeirão Preto.

Colnago, N. A. S. (2014). Programa de orientação para pais de crianças com síndrome de down: Modelos de práticas de educação e de desenvolvimento. In V. L. Israel \& M. B. L. Pardo (Orgs.). Desenvolvimento Infantil: Orientação a Pais e Professores (pp. 41-58). Porto Alegre: Redes Editora.

D`Abreu, L. C. F. \& Marturano, E. M. (2010). Associação entre comportamentos externalizantes e baixo rendimento escolar: Uma revisão de estudos prospectivos e longitudinais. Estudos de Psicologia, 15, 43-51. http://dx.doi.org/ 10.1590/S1413-294X2010000100006

Dessen, M. A. (2010). Estudando a família em desenvolvimento: desafios conceituais e teóricos. Psicologia: ciência e profissão, 30, 202-219. doi: 10.1590/S1414-98932010000500010. http://dx.doi.org/10.1590/S141498932010000500010

Dessen, M. A. \& Lewis, C. (1998) Como estudar a "família” e o "pai”?. Paidéia, 8, 105-121. http://dx.doi.org/10.1590/ S0103-863X1998000100009

Friedberg, R. D. \& McClure, J. M. A. (2004). Prática clínica de terapia cognitiva com crianças e adolescentes. Trad. Cristina Monteiro. Porto Alegre: Artmed.

Mcmahon, R. J. (1999). Treinamento de pais. In V. E. Caballo (Org.). Manual de Técnicas de Terapia Comportamental e Modificação do Comportamento (pp. 399-422). São Paulo: Santos Livraria Editora.

Pardo, M. B. L. \& Carvalho, M. M. S. B. (2011). Grupo de orientação de mães no contexto de uma clínica-escola. Paidéia, 21, 93-100. http://dx.doi.org/10.1590/S0103-863X2011000100011

Pardo, M. B. L. \& Carvalho, M. M. S. B. (2012). Grupos de orientação de pais: estratégias para intervenção. Contextos Clínicos, 5, 80-87. http://dx.doi.org/10.4013/ctc.2012.52.02

Pardo, M. B. L., Carvalho, M. M. B. S., \& Santos, A. B. (2014). Grupo de orientação a pais: otimizando a interação pais-filhos. In V. L. Israel \& M. B. L. Pardo (Orgs.). Desenvolvimento infantil: Orientação a pais e professores (pp. 41-58). Porto Alegre: Redes Editora.

Patias, N. D., Siqueira, A. C., \& Dias, A. C. G. (2013). Práticas educativas e intervenção com pais: A educação como proteção ao desenvolvimento dos filhos. Mudanças - Psicologia da Saúde, 21, 29-40. http://dx.doi.org/10.15603/21761019/mud.v21n1p29-40

Salvo, C. G., Silvares, E. F. M., \& Toni, P. M. (2005). Práticas educativas como forma de predição de problemas de comportamento e competência social. Estudos de Psicologia (Campinas), 22, 187-195. http://dx.doi.org/10.1590/ S0103-166X2005000200008

Silvares, E. F. M (2000). Avaliação e intervenção clínica comportamental infantil. In Silvares. E. F. M. (Org.). Estudos de caso em psicologia clínica comportamental infantil (Vol. 1). Campinas, SP: Papirus, p. 13-29.

Valentini, F. \& Alchieri, J. C. (2009). Modelo clínico de estilos parentais de Jeffrey Young: Revisão da literatura. Contextos Clínicos, 2, 113-123. http://dx.doi.org/10.4013/ctc.2009.22.06

Weber, L. N. D., Brandenburg, O. J., \& Salvador, A. P. V. (2006). Programa de qualidade na interação familiar (PQIF): Orientação e treinamento para pais. Psico, 37, 139-149.

Autores:

MARia Benedita Lima PARDo - Pós-doutorado em Educação Escolar, Departamento de Psicologia, Universidade Federal de Sergipe (UFS)

MARgarida MARia Silveira Britto de CARVAlHo - Especialização em Educação Especial, Departamento de Psicologia, UFS.

ARIANE DE BRITO - Mestranda em Psicologia Social, Programa Pós-Graduação em Psicologia Social, UFS.

Luciana Priscila Lima da Silva - Graduada em Psicologia, Departamento de Psicologia, UFS.

Endereço para correspondência:

Maria Benedita Lima Pardo

Rua Vila Cristina, 68, apto. 301

CEP 49015-000 Aracaju, SE, Brasil

Recebido em: 12.09.14

Aceito: 06.10.15

Psico, Porto Alegre, v. 46, n. 4, pp. 423-431, out.-dez. 2015 